\title{
Immunohistochemical expression of progesterone receptor and C-erb-B2 in cervical squamous cell carcinoma and epithelial dysplasia
}

\author{
Emine Zeynep Tarini ${ }^{1 *}$, Hasan İlyas Özardali ${ }^{1}$ \\ ${ }^{1}$ UNIVERSITY OF HEALTH SCIENCES, SANLIURFA MEHMET AKIF INAN EDUCATION AND RESEARCH HOSPITAL, DEPARTMENT OF PATHOLOGY, HALILIYE, SANLIURFA, TURKEY
}

\begin{abstract}
Objective. We aimed to demonstrate whether the immunohistochemical expression of $\mathrm{C}$-erb-B2 and progesterone receptors are valuable in the diagnosis of intraepithelial cervical neoplasia and squamous cell carcinoma. Methods and Results. Our retrospective study, a total of 84 cases diagnosed as squamous cell carcinoma and cervical intraepithelial neoplasia during 2005-2009, at the pathology department of Harran University, was investigated and stained with immunohistochemistry. Progesterone receptor was stained positive in 5 of 21 cervical intraepithelial neoplasia I. As a result of the statistical analysis (SPSS statistic 15.0), a significant correlation was found for positive progesterone receptors. No positive staining was seen in any of the cases with CerbB2 ( $>00,05)$. Conclusions. In this study, it was concluded that positive progesterone receptors can be used to distinguish cases of cervical intraepithelial neoplasia I from other dysplasia and carcinoma, while Cerb-B2 has not been shown to be useful in distinguishing between these lesions.
\end{abstract}

\author{
Category: Original Research Paper \\ Received: January 23, 202 \\ Accepted: March 18, 2021 \\ Published: May 10, 2021 \\ Keywords: \\ cervix, dysplasia, progesterone, C-erb-B2 \\ * Corresponding author: \\ Emine Zeynep Tarini \\ University of Health Sciences, Şanliurfa Mehmet Akif İnan \\ Education and Research Hospital, Department of pathology, \\ Ertuğrul St., Haliliye, Şanlıurfa, Turkey, 63300 \\ E-mail: eztarini@hotmail.com
}

\section{Introduction}

Cervical intraepithelial neoplasia (CIN) is a group of neoplasms which include in association both dysplasia and carcinoma in situ. Such lesions are often encountered in women during the reproductive period. Cervical squamous cell carcinoma (SCC) is the most common malignancy of the female genital tract in several countries [1].

Cervical carcinoma is the second type of cancer diagnosed in women after breast cancer. It represents 10$15 \%$ of all malignancies observed in women [2]. In many developed countries, the diagnosis of cervical cancer has declined in the last 30-40 years since the introduction of cervical screening programs. However, in many countries, the mortality rate has remained the same or increased in women under the age of 45 . Cervical carcinoma is the second major cause of carcinoma-related deaths in women [3].

Numerous epidemiological studies identified several risk factors in the development of cervical carcinoma and precursor lesions, mainly sexually transmitted diseases $[3,4]$. Factors such as early sexual intercourse (especially under 16 years of age), human papillomavirus, early childbirth, polygamy, increased parity, male partner with multiple sexual partners are in fact superposable and highly related each other [5].

The progesterone receptor (PR) is an intracellular protein that selectively binds to the progesterone hormone molecule present in the blood, forms the hormone receptor complex and introduces into the cell progesterone, depending on its concentration. The active hormonereceptor complex binds to short DNA sequences, called intranuclear hormone response elements, and stimulates transcription that makes possible the physiological action of hormone [4,6]. C-erb-B2, known as HER2/neu, is the transmembrane glycoprotein of the tyrosine kinase receptor family, which controls cell growth. It does not have a specific ligand, and the gene of this protein is located on chromosome 17. It acts as a coreceptor for many growth factors and exhibits tyrosine kinase activity. 
Amplification was detected due to amino acid changes with point mutations in C-erb-B2 gene. When it is overexpressed, it is considered an oncogene [7,8]. C-erbB2 expression is present in several carcinomas, such as the ovaries, breast, endometrium, lung, bladder and gastrointestinal tract [9]. It has been reported in recent years that several additional examination methods can be used to differentiate between different CIN lesions, and from other benign and malignant lesions. Such method is immunohistochemistry. Immunohistochemical analysis of various markers has been performed on CIN and SCC lesions, and some of them proved to be valuable in the diagnosis of these lesions [1].

The aim of this study was to demonstrate by immunohistochemical methods whether the presence of Cerb-B2 and progesterone receptor is valuable in the diagnosis of CIN lesions, and SCCs originating from the squamous epithelium of the cervix.

\section{Materials and Methods}

A total of 84 cases, diagnosed with cervical SCC and dysplasia in the Department of Pathology of Harran University School of Medicine, between 2005 and 2009, were included in the study. 40 of our cases consisted in cervical biopsy, 29 of them involved Loop Electrosurgical Excision Procedure (LEEP) and 15 of them implied the hysterectomy piece study.

The blocks and slides belonging to the cases were removed from the archives and re-cuts were taken from the required blocks and stained with hematoxylin \& eosin. Hematoxylin \& eosin-stained lamellae of the cases were reevaluated and reclassified as invasive SCC, CIN III, CIN II and CIN I. One appropriate block for each case was selected for immunohistochemical evaluation.

Sections were taken from paraffin blocks for immunohistochemical study. Immunohistochemical staining was performed using Progesterone receptor (NeoMarkers Catalog No. PgR 636) and C-erb-B2 (NeoMarkers Catalog No. RM 9103-R7). DAB chromogen was used as a chromogen.

In our study, endometrium tissue for progesterone receptor and infiltrative ductal carcinoma case for C-erbB2 were used as positive control.

Progesterone receptor scoring was performed on nuclear staining. Negative nuclear staining was considered as "score 0 " and positive nuclear staining as "score 1".

C-erb-B2 scoring was performed according to cytoplasmic membrane staining in cells. Negative membrane staining was scored as 0 and positive membrane staining as score 1 . The correlation between progesterone receptor and C-erb-B2 scores on one hand, and dysplasia and carcinoma on the other hand was assessed using ChiSquare test in the SPSS 11 package program. Values of $\mathrm{p}<0.05$ were considered significant.

\section{Results}

A total of 84 cases were studied. The cases ranged from 22-76 years and the average age was 47 years. After histopathological evaluation, CIN1 was found in 21 cases, CIN2 in 21 cases, CIN3 in 21 cases and invasive SCC in 21 cases. The distribution of the cases according to age groups and diagnosis is presented in Table 1.

Table 1. The distribution of the cases according to the age group

\begin{tabular}{|l|c|c|c|c|c|c|c|}
\hline Age & $20-29$ & $30-39$ & $40-49$ & $50-59$ & $60-69$ & $70-79$ & Total \\
\hline Number of cases & 7 & 19 & 27 & 18 & 6 & 7 & 84 \\
\hline$\%$ & 8 & 22 & 32 & 23 & 7 & 8 & 100 \\
\hline
\end{tabular}

Of 21 CIN I cases, the youngest was 22 years old, the oldest was 71 years old, and the mean age was 39 years. Of 21 CIN II cases, the youngest was 29 years old, the oldest was 74 years old, and the mean age was 44 years. In a total of 21 CIN III cases, these ages (youngest/ oldest/ mean) were 36, 75 and 46 respectively. In invasive carcinoma cases, these values were found as 46, 76 and 57 respectively.

Of the total 84 cases examined, 5 were positive for progesterone receptor. All positive cases were CIN I lesions (Figure 1) and no positive staining was observed in CIN II, III and invasive SCC cases. The results are presented in Table 2. There was a significant difference in PR expression between CIN I group and other groups ( $\mathrm{p}=$ 0.001 ). C-erb-B2 staining was not detected in any of the 84 cases examined. The results are shown in Table 3 for $\mathrm{C}$ -
erb-B2 scores (CIN: Cervical intraepithelial neoplasia, SCC: squamous cell carcinoma).

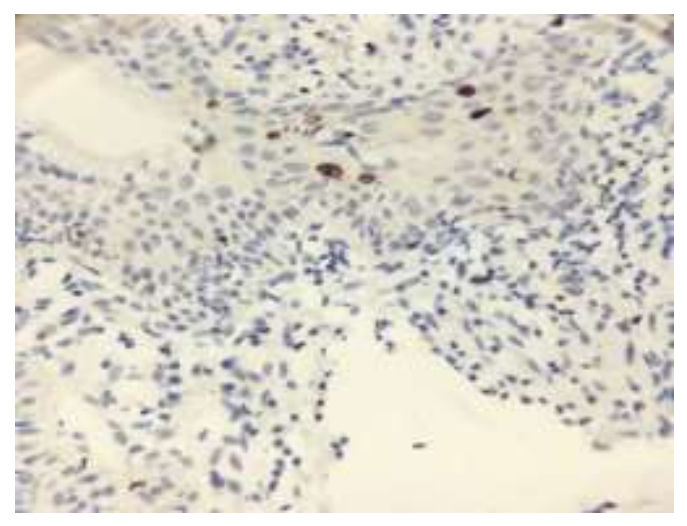

Figure 1. Progesterone receptor positive in Cervical intraepithelial neoplasia I (CIN I) (İHK, X100) 
Table 2. Progesterone receptor scores (CIN: Cervical intraepithelial neoplasia, SCC: squamous cell carcinoma)

\begin{tabular}{|l|c|c|c|c|c|}
\hline Score & CIN I & CIN II & CIN III & $\begin{array}{c}\text { Invasive } \\
\text { SCC }\end{array}$ & Total \\
\hline Positive & 5 & 0 & 0 & 0 & 5 \\
\hline Negative & 16 & 21 & 21 & 21 & 79 \\
\hline Total & 21 & 21 & 21 & 21 & 84 \\
\hline
\end{tabular}

Table 3. There was no difference between the groups in C-erb-B2 expression ( $\mathrm{p}>0,05)$.

\begin{tabular}{|l|c|c|c|c|c|}
\hline Score & CIN I & CIN II & CIN III & $\begin{array}{c}\text { Invasive } \\
\text { SCC }\end{array}$ & Total \\
\hline Positive & 0 & 0 & 0 & 0 & 0 \\
\hline Negative & 21 & 21 & 21 & 21 & 84 \\
\hline Total & 21 & 21 & 21 & 21 & 84 \\
\hline
\end{tabular}

\section{Discussions}

Invasive cervical carcinoma is the seventh malignant tumor among all cancers and the second malignant tumor in females after breast cancer. It is the first malignancy among gynecological cancers. Around the world, 465.000500.000 new cases are detected each year, causing the death of more than 300.000 women every year [10]. CIN lesions were detected in 1.4- $4 \%$ of cervical screening studies. CIN III lesions constitute $0.2-2.7 \%$ of all these lesions [11]. CINs are usually seen in women of childbearing age. Invasive cervical carcinoma usually follows after a pre-invasive disease (CIN I-II-III) [12].

Cervical carcinomas can be seen in women at any age (17-90y). However, most tumors arise between decades 4 and 6. CIN lesions usually appear in the mid-twenties, carcinoma in situ at 25-35 years, and invasive carcinomas after 40 years. It has been reported that the incidence of CIN lesions in women under 20 has increased in recent years, due to the increase in the number of women with a first sexual intercourse under 15 and the number of polygamous women [13]. The incidence of SCC after seventy-five years of age is three times higher than before twenty-five years of age. Some studies in recent years show that the average age of cervical cancer has decreased. This is closely linked to changes related to onset of early sexual activity, and the increase in effective methods of cytological screening $[1,7]$.

In our study the youngest patient was 22 years old, the oldest was 76 years old and the mean age was 47 years. The mean age of CIN I cases in our study was 39 years, the mean age of CIN II cases was 44 years and the mean age of CIN III cases was 46 years. In the case of invasive carcinoma, the mean age was 57 years. These findings are consistent with the literature and support the view that CIN lesions present a prolonged progression.

PR consists of two different structures, alpha and beta. Studies related to progesterone receptor show that this receptor is present in the cell, namely in the nucleus and cytoplasm. This receptor is thought to be involved in stimulating cell proliferation. By immunohistochemical and ultrastructural methods, it can be shown that hormone receptors are placed under or in the nuclear membrane $[6,14]$.

PR has been investigated in several studies, especially in breast and endometrial carcinoma, and has been identified as an important prognostic factor in these tumors $[15,16]$. In addition, progesterone receptors are known to be important in determining the prognosis and treatment protocol in a group of neoplastic diseases, such as solitary pleural fibrous tumor, hepatocellular carcinoma, and meningioma. PR-positive tumors respond well to hormonal therapy, which is associated with a better prognosis $[4,6]$.

$\mathrm{PR}$ is present in ectocervical parabasal cells, endocervical mucosal and glandular cells and metaplastic cells. The receptors in the parabasal cells show immunohistochemically strong expression in the luteal phase of the menstrual cycle and in pregnancy, but weak or no expression in the proliferative phase. In the ectocervical stroma, the PR in the nucleus of fibroblast-like cells can be shown at each stage of the menstrual cycle [17]. Physiologically, this receptor functions less after menopause than during the premenopausal period [18].

In cervical CCS, the investigation of the presence of PR was first performed in 1970s [19]. Many studies show that PR positivity has a very broad range (0-100\%). This is due to the fact that PR changes depending by stages of the menstrual cycle, pre-postmenopausal period, histological type of tumor and DNA ploidy [20]. The positivity of PR in cervical adenocarcinomas is observed in 1/4 of cases [4].

In the PR study of Park et al. including 30 cases with normal cervical tissue, $5 \mathrm{CIN}$ and 10 cervical carcinomas, the PR expression was shown in 16 normal cervix (61\%), 4 CIN cases $(80 \%)$ and 8 carcinomas $(80 \%)$, while the rate of PR was similar in normal tissue and carcinoma. In the same study, the staining rate was higher in nonkeratinized histological subtypes of cervical carcinomas than in keratinized subtypes [18].

Coelho et al. reported positive immunohistochemical staining for normal and tumorous tissues at 5 CIN I, 3 CIN II, 9 CIN III and 4 SCC cases. However, none of these cases presented epithelial staining [20]. In a study of Monsonego et al. in CIN I, II, III lesions and SCC cases, the positivity level of CIN lesions was higher than for invasive carcinomas and they concluded that there was a 
partial role of progesterone in malign transformation of the cervix [21]. Çamlıbel and Demircan, in their study investigating $\mathrm{PR}$ in cervical cancers, found positive staining in 4 of 10 cervical cancers (40\%) [22]. In a study conducted by Konishi et al., PR was expressed in 19 of 26 CIN cases and 13 of 22 invasive carcinoma cases [23].

In his study, Tangjitgamol et al evaluated the immunoreactivity of PR in cervical carcinomas, and only 2 cases showed focal expression [8]. Many studies investigated the effect of hormone receptor expression on the prognosis of cervical carcinoma; the presence and intensity of the hormone receptor shows little or no effect on the development, prognosis, and survival of SCC [19]. In our study, PR was positive only in 5 of the CIN I cases, and negative in the other 79 cases. Staining in the stromal cells was detected in a majority of cases. The statistical rates resulted from our study is relatively similar to that of Monsonego, Christmas and Tangjitgamol.

We think that the significance of PR detected in CIN I lesions may be helpful in differentiating CIN I from other dysplasia and squamous cell carcinoma, but not in normal squamous epithelium because of the presence of PR positivity in normal cervical parabasal and basal cells.

As a result, 5 of 84 cases were positive in immunohistochemical examination with $\mathrm{PR}$, and the overall positivity rate was found as $5.8 \%$. All PR-positive cases were CIN I, and the overall positive rate was $23.8 \%$ in these cases. Our results suggest that PR may be valuable in the diagnosis of CIN I cases, being able to distinguish CIN 1 cases from CIN II, III, and squamous cell carcinoma.

None of the cases had positive staining with C-erb-B2 in the immunohistochemical examination.

\section{Conclusions}

As a conclusion, cervical intraepitelial neoplasia is one of the leading causes of cervix cancer. Progesterone receptor may be helpful in the distinction between other dysplasias(CIN II and CIN III) and squamous cell carcinoma of cervical intraepithelial neoplasia I cases. However, Cerb B2 is not useful for distinguishing between precancerous and cancerous lesions in cervix.

\section{Conflict of interest disclosure}

There are no known conflicts of interest in the publication of this article. The manuscript was read and approved by all authors.

\section{Compliance with ethical standards}

Any aspect of the work covered in this manuscript has been conducted with the ethical approval of all relevant bodies and that such approvals are acknowledged within the manuscript.

\section{References}

1. Cheung TH, Chung TK, Lo KW, Yu MY, Krajewski S, Reed JC, Wong YF. Apotosis-related proteins in cervical intraepithelial neoplasia and squamous cell carcinoma of the cervix. Gynecol Oncol. 2002;86(1):14-8. doi: 10.1006/gyno.2002.6655

2. Mahadevia PS, Tanaka K, Fineberg S. Rosai and Ackerman's Surgical Pathology. 9th edition author: Juan Rosai Mosby, Edinburgh, 2004. Diagnostic Cytopathology 2006;34(5): 382-383.

doi: $10.1002 / d c .20292$

3. Lewis MJ. A Situational Analysis of cervical cancer in Latin America and the Caribbean. Washington, D.C. PAHO, 2004: 1-18. ISBN: 9275125317

4. Williams PL, Warwick R. Gray's Anatomy. 36th ed. Newyork: Churchill Livingstone, 1980; 1428-1432.

5. Yumru E, Bozkurt M, Erşen İ, Önal A. Condyloma accumınata cases characteristics the evalvation of the clinical symptoms and treatment with the current. Ege Journal of Medicine. 2006;45(2):101-107.

6. Pretorius RG, Zhang X, Belinson JL, Zhang WH, Ren SD, Bao YP, Qiao YL. Distribution of cervical intraepithelial neoplasia 2, 3 and cancer on the uterine cervix. J Low Genit Tract Dis. 2006;10(1):45-50. doi: 10.1097/01.lgt.0000192697.31291.42

7. Scanlon VC, Sanders T. Essentials of anatomy and physiology. Fifth ed. Philadelphia: FA. Davis Company, 2007; 462-470. ISBN-10: 9780803639577

8. Boardman LA, Weitzen S, Stanko C. Atypical squamous cells of undetermined significance, human papillomavirus, and cervical intraepithelial neoplasia 2 or 3 in adolescents: ASC-US, age, and high-grade cervical neoplasia. J Low Genit Tract Dis. 2006;10(3): 140-5. doi: 10.1097/00128360-200607000-00004

9. Chapman GW Jr. Patterns of cervical carcinoma in women of advanced age. J Natl Med Assoc. 1997; 89(12):801-4.

10. Regauer S, Reich O. CK17 and p16 expression patterns distinguish (atypical) immature squamous metaplasia from high-grade cervical intraepithelial neoplasia (CIN III). Histopathology. 2007;50(5):629-35. doi: 10.1111/j.1365-2559.2007.02652.x

11. Kumar V, Fausto N, Abbas AK. Robbins \& Cotran Pathologic Basis of Disease. 7th ed. Philadelphia: Elsevier Saunders, 2005; 1072-1079. ISBN-10: 0721601871

12. Hellweg GD, Doeberitz K, Trunk MJ. Color Atlas of Histopathology of the Cervix Uteri. Second ed. Berlin Heidelberg; Springer, 2006; 7-56, 82-168. ISBN: 9783-540-29726-0

13. Mills SE, Carter D, Greenson JK, et al. Stenberg's Diagnostic Surgical Pathology. Fourth ed. Philadephia: 
Lippincott Williams \& Wilkins 2004; 2377-2434. ISBN-10: 0781740517

14. Ambros RA, Kurman RJ. Current concepts in the relationship of human papillomavirus infection to the pathogenesis and classification of precancerous squamous lesions of the uterine cervix. Semin Diagn Pathol. 1990;7(3):158-72.

15. Miller K, Blumenthal P, Blanchard K. Oral contraceptives and cervical cancer: critique of a recent review. Contraception. 2004;69(5):347-51. doi: 10.1016/j.contraception.2003.12.012

16. Shields TS, Brinton LA, Burk RD, Wang SS, Weinstein SJ, Ziegler RG, Studentsov YY, McAdams M, Schiffman M. A case-control study of risk factors for invasive cervical cancer among U.S. women exposed to oncogenic types of human papillomavirus. Cancer Epidemiol Biomarkers Prev. 2004;13(10):1574-82.

17. Özgül N. Cervical cancer epidemiology, etiology, pathogenesis and screening programs in Turkey. İstanbul; Medya Tower. 2007:6-15.

18. Kalof AN, Cooper K. Our approach to squamous intraepithelial lesions of the uterine cervix. J Clin Pathol. 2007;60(5):449-55. doi: 10.1136/jcp.2005.036426
19. Fuchs I, Vorsteher N, Bühler H, Evers K, Sehouli J, Schaller G, Kümmel S. The prognostic significance of human epidermal growth factor receptor correlations in squamous cell cervical carcinoma. Anticancer Res. 2007;27(2):959-63.

20. de Villiers EM, Gissmann L, zur Hausen H. Molecular cloning of viral DNA from human genital warts. $J$ Virol. 1981;40(3):932-5. doi: 10.1128/JVI.40.3.932935.1981

21. Münger K, Baldwin A, Edwards KM, Hayakawa H, Nguyen CL, Owens M, Grace M, Huh K. Mechanisms of human papillomavirus-induced oncogenesis. $J$ Virol. 2004;78(21):11451-60. doi: 10.1128/JVI.78.21.1145111460.2004

22. Tranberg M, Jensen JS, Bech BH, Andersen B. Urine collection in cervical cancer screening - analytical comparison of two HPV DNA assays. BMC Infect Dis. 2020;20(1):926. doi: 10.1186/s12879-020-05663-7

23. Di Donato V, Caruso G, Petrillo M, Kontopantelis E, Palaia I, Perniola G, Plotti F, Angioli R, Muzii L, Benedetti Panici P, Bogani G. Adjuvant HPV Vaccination to Prevent Recurrent Cervical Dysplasia after Surgical Treatment: A Meta-Analysis. Vaccines (Basel). 2021;9(5):410. doi: 10.3390/vaccines9050410 